\title{
Respiratory Function in Children with Nephrotic Syndrome: Comparative evaluation of Impulse Oscillometry and Spirometry
}

\author{
Fatih Kilci ${ }^{1}$, Zeynep $\mathrm{Uyan}^{2}$, Mehtap Çelakıl ${ }^{3}$, Kenan Dogan ${ }^{1}$, and Kenan Bek ${ }^{1}$ \\ ${ }^{1}$ Kocaeli University \\ ${ }^{2}$ Koç University \\ ${ }^{3}$ Kocaeli Universitesi Tip Fakultesi
}

March 4, 2021

\begin{abstract}
Abstract Aim: To evaluate the respiratory functions of children with nephrotic syndrome (NS) by IOS and its correlation with spirometry. Methods: Fifty-five NS patients aged 3-18 years were included as the study group and 40 healthy children of the same age formed the control group. Patients were divided into nephrotic phase (first attack and relapse) and remission. Demographic, anthropometric and laboratory data of the children were recorded. Respiratory functions were evaluated by IOS and spirometry. Children over 6 years old performed both IOS and spirometry while children under 6 years performed only IOS. Results: The R (R5\%, R10\%, R5-20) and AX and Z5\% values of IOS in patients with nephrotic phase were higher than remission patients and control group while spirometry indices of FEV1\%, FEV1/FVC, PEF\% and MEF25-75\% were lower. FEV1\% showed negative correlation with R5\%, R10\%, R15\%, X10\% and X15\% results, FEV1/FVC\% showed negative correlation with R5\%, R5-20 and X15\% results, FVC showed negative correlation with X10\% results, MEF25-75\% showed negative correlation with, R5\%, R10\%, R5-20, X15\%, F res, Z5\% and AX results. Conclusion: Our study demonstrated that respiratory functions measured by IOS and spirometry were affected at the time of nephrotic phase in NS patients. And IOS, a novel method easily applicable even in small children, is a valuable and reliable tool to detect this condition; given its good correlation with spirometry. Keywords Nephrotic syndrome, Respiratory functions, Spirometry, Impulse Oscillometry
\end{abstract}

\section{Hosted file}

27.02.2021.pdf available at https://authorea.com/users/399397/articles/511942-respiratoryfunction-in-children-with-nephrotic-syndrome-comparative-evaluation-of-impulseoscillometry-and-spirometry

\section{Hosted file}

Final tables.pdf available at https://authorea.com/users/399397/articles/511942-respiratoryfunction-in-children-with-nephrotic-syndrome-comparative-evaluation-of-impulseoscillometry-and-spirometry 